\title{
Personality and Reputation: A Complex Relationship in Virtual Environments
}

\author{
Stefania Collodi ${ }^{1, *}$, Sara Panerati ${ }^{1}$, Enrico Imbimbo ${ }^{1}{ }^{(1)}$, Federica Stefanelli ${ }^{1}$, \\ Mirko Duradoni ${ }^{2}$ (1) and Andrea Guazzini ${ }^{1,3}$ \\ 1 Department of Educational Science and Psychology, University of Florence, Via di San Salvi 12, \\ 50135 Firenze, Italy; sara.panerati@gmail.com (S.P.); enrico.imbimbo@unifi.it (E.I.); \\ federica.stefanelli@unifi.it (F.S.); andrea.guazzini@unifi.it (A.G.) \\ 2 Department of Information Engineering, Via S. Marta 3, 50139 Firenze, Italy; mirko.duradoni@unifi.it \\ 3 Center for the Study of Complex Dynamics (CSDC), University of Florence, Via di San Salvi 12, \\ 50135 Firenze, Italy \\ * Correspondence: collodistefania@gmail.com
}

Received: 5 November 2018; Accepted: 28 November 2018; Published: 1 December 2018

\begin{abstract}
Online reputational systems are nowadays widely and effectively adopted by several online platforms to support and improve peoples' interactions and communication. Despite the research approached and modeled social dynamics of reputational systems in different domains, adopting different frameworks, the role played by psycho-social factors, and personality traits, determining the individual susceptibility to online reputation is still elusive. To study such mediation effects, we implemented a modified online version of the Ultimatum Game, in which participants (215 adolescents) played before as proposers, and then as responders, always knowing the reputation of their interactors. Furthermore, after the reception phase, participants could evaluate the received offers, giving positive or negative feedback to their proposers. Despite the participants' belief they were playing with their schoolmates, the interactors' role was always fulfilled by bots characterized by standardized behaviors. Our results show how psychological traits influence the participants' behavior in all the game phases, as well as in the rating dynamics. Reputation seems to have a direct effect only in the allocation behavior, while, in regards the other dynamics of the game (i.e., acceptance and rating), it comes into play in a complex interaction with the psychological dimensions.
\end{abstract}

Keywords: reputation; personality; Ultimatum Game; online reputation susceptibility

\section{Introduction}

In the fourth century B.C., Aristotle affirmed: "man is by nature a social animal; an individual who is unsocial naturally and not accidentally is either beneath our notice or more than human". Over the last three decades, according to Kimbrough and Vostroknutov [1], economists have uncovered robust evidence of human sociability in simple, anonymous, laboratory games. A frequent violation of the selfish profit maximization predictions appear to arise in the individuals' systematic tendencies towards reciprocity and fair outcomes [1,2]. These factors seem to play a central role in orienting peoples' behavior in economic games since individuals' social preferences are strongly driven by social norms-not only by material rewards. Research already explored how pro-social behaviors in some context could not represent a violation of the rational choice principles, but rather the evidence that people are affected by internalized social norms, and how the context can activate those norms [1]. To study such complex social dynamics, frequently the framework of bargaining games $[3,4]$ has been adopted. Within experimental economics, the Ultimatum Game (UG) of Güth et al. [5] is one of the most studied, with a total of more than 2800 citations on Google Scholar [6]. In this game, a sum 
of money is given to a player (proposer) who has to divide it between himself and another player (responder). If the responder accepts the offer, money is split as the first player decided; if they refuse it, nobody earns anything. Despite the Rational Choice and the Expected Utility Theory postulate that a rational proposer should offer the least amount allowed, and a rational responder should accept all the received offers, people seem not to behave in this way. Usually, proposers split the stakes fairly, while the responders typically reject unfair offers [7]. In particular, proposers usually offer the 40-50\% of the total sum, while responders usually reject offers below 30\% of the total amount [8]. In this sense, the Ultimatum Game behavior appears to be characterized by the combination of inequity aversion and strategic self-interest [9]. According to Castelli et al. [10], the offer rejection in the UG could be driven not only by inequity aversion but also by sensitivity to social norms of fairness, depending on the reasons that brought the responder to refuse the proposal. It seems that while the inequity aversion motives are independent of the procedure that generated the offer, the sensitivity to social norms of fairness is bound to the offer generation process, and the personal empirical and normative expectations. Fairness has been defined as a social norm by Feng et al. [11], and one of the factors that seem to promote it is Reputation [12]. Previous research already revealed how human beings are willing to give up on some fitness to maintain and improve their reputation within their social environment [13], favoring the evolution of fairness in social dilemmas [12]. In several economic games [14,15], reputation effects have been revealed to affect subjects' normative expectations, and to influence the subjects' fairness perception, ultimately determining people's behavior [16]. Individuals tend to conform to the norms when they perceive that breaking them could lead to social drawback. At the same time, people tend to ignore norms, if violating them does not have negative consequences [10]. Thus, reputation can be considered a source of normative influence [17], capable of predicting if individuals would tend to adhere (or not) to the social norms [18], and can also be conceptualized as a proxy for local norms [19]. Within such a scenario, literature already showed that people are not equally susceptible to social norms [20], and how part of this variation can be attributed to individual differences [6,21-23]. Several contributions have put the Big Five Personality Factor model in relation with social preferences and the tendency to adhere to social norms in real environments [24]. Among the different personality traits, Openness, Extraversion, and Neuroticism seem to reduce the individual susceptibility to social influence, while Conscientiousness and Agreeableness appear to increase the adhesion to the social norms [25]. According to the literature, another personality trait that plays an important role in normative influence is Social Dominance Orientation (SDO). People with high SDO values seem to be more susceptible to social norms, such as fairness and reputation [26]. Finally, for what concerns Anxiety, the research of Wu et al. [27] demonstrated that people with a higher score on this trait were less susceptible to social norms in Computer-mediated communication (CMC). Beyond these contributions, there is still a gap in the literature that prevents people from deepening the knowledge on the relationship between personality traits and the adherence to social norms when an online reputational system is provided. Consequently, our purpose is to investigate peoples' susceptibility to reputation through a modified version of the Ultimatum Game online, in which subjects not only play as proposers and responders but also have the possibility to evaluate (i.e., rating with a like or a dislike) the offers they received, giving a feedback to their proposer. Since adolescents show a peculiar and varied social norms adhesion dynamics [28-30], we selected a sample of teenagers with an average age of 15.81 years old for our study. Moreover, realizing the experiment within an online setting, specific features of this environment come into play [31]. In particular, the effects of such characteristics (i.e., deindividuation) can lead to a different pattern of social norms adherence [32]. Therefore, interdependence between subjects' characteristics, social settings' features, and social norms have to be considered together in order to understand the complex dynamics determining the online reputation effects on subjects' behavior. In our study, we explicitly hypothesize an effect of each personality traits in determining reputation susceptibility in the donation phase and the reception phase of the online UG. Furthermore, we also suppose that the psychological traits could play a role in the participants' tendencies to positively or negatively evaluate 
the received offers. Our preliminary findings suggest an effect of the interaction between the players' psychological traits, and the existence of a reputational system, on the players' allocation and reception behaviors in the online UG, as well as on the evaluations of the received offers. In order to facilitate the reading, the paper is organized as follows. Firstly, we present our experimental hypothesis divided into three subsections, respectively dedicated to Donation, Acceptance, and Rating behavior. Then we describe the experimental methods and procedures, followed by the results of our study. Finally, the experimental evidence are discussed in the last section.

\subsection{Hypothesis}

As showed in the Table 1, all the variables have been taken into account in relation with fairness considerations, and social norms adherence, for all the phases of our online modified UG. In order to streamline the handling, we split the hypotheses into three categories: Donation (H1), Acceptance (H2), and Rating (H3) behavior.

Table 1. Summary of Experimental Hypotheses: in the table are reported the literature predictions on the effects of reputation and psychological traits in interaction with the reputation (R), on Donation, Acceptance, and Rating.

\begin{tabular}{|c|c|c|c|}
\hline \multicolumn{4}{|c|}{ Experimental Hypothesis Table } \\
\hline Variable & $H_{1}$ : Donation & $\mathrm{H}_{2}:$ Acceptance & $H_{3}$ : Rating \\
\hline Reputation (R) & + & + & + \\
\hline Openness * $\mathrm{R}$ & - & - & 0 \\
\hline Extraversion * $\mathrm{R}$ & - & - & 0 \\
\hline Neuroticism * $\mathrm{R}$ & - & - & 0 \\
\hline Conscientiousness ${ }^{*} \mathrm{R}$ & + & + & + \\
\hline Agreeableness * $\mathrm{R}$ & + & + & + \\
\hline State Anxiety ${ }^{*} \mathrm{R}$ & 0 & - & - \\
\hline Social Dominance Orientation * $R$ & + & + & + \\
\hline
\end{tabular}

\subsubsection{H1: Donation}

Since people appear to be more pro-social towards high reputation interactors [33], we hypothesize that also in our game proposers would be more generous towards high Reputation responders. Furthermore, for what concerns psychological traits, the literature showed that individuals with a high score of Conscientiousness [25], Agreeableness [34-36], and Social Dominance Orientation [26] appear to be more susceptible to social norms (e.g., fairness and reputation). Therefore, we assume to detect an influence of responders' reputation in money allocation in proposers with high levels of these traits. On the other side, since individuals with high values of Openness [25], Extaversion [25], Neuroticism [25], and State Anxiety [27] seem to be less sensitive to social norms, we would expect a negative effect, or no effect at all, of the reputation on proposers' donation behavior.

\subsubsection{H2: Acceptance}

Reputation builds on interactions, so if someone has a good reputation, it would be probably mean that they behaved well towards others, respecting the social norms of the group [37]. Since people appear willing to engage in costly punishment towards those who violate such norms (i.e., unfair proposers) [38], we hypothesize that they will reward proposers with high reputation, accepting more probably their offers. At the same time, fairness sensitivity and norms adherence that seem to characterize individuals with high Conscientiousness [25], Agreeableness [34-36], and Social Dominance Orientation [26] values, could be expected to promote the same behavior. Finally, for what concerns Openness [25], Extraversion [25], Neuroticism [25], and State Anxiety [27] we assume that they will not influence or that they will affect negatively the responders' tendency to be susceptible to 
proposers' reputation, considering that literature suggests that people with those psychological traits seem to be not very sensitive to fairness.

\subsubsection{H3: Rating}

From recent literature, contributions emerge that people with good reputation tend to be more positively evaluated from their interactors also in virtual environments [39], so we hypothesize that Reputation could influence the responders' rating behavior in our UG online version. Even players with a high score of Conscientiousness [25] and Agreeableness [25], given their susceptibility to social norms, could be affected by proposers' reputation. Considering the SDO, in accordance with Armstrong [26] findings, we hypothesize that high SDO players would rate positively offers coming from good reputation proposers. For what concerns Openness [25], Extraversion [25], Neuroticism [25], and State Anxiety [27], we assume that responders with high values of these psychological traits will be negatively (or will not at all) influenced by the proposers' reputation in rating their offers, given the reduced susceptibility to social norms that characterize those players.

Summarizing, in the light of the literature review, it is possible to hypothesize that the following assumptions might be true for our modified online Ultimatum Game.

Hypothesis 1. The amount offered is affected by the psychological traits of the proposers, and the presence of the responders' reputation.

Hypothesis 2. The players' acceptance behavior is affected by their psychological traits and by the presence of a reputation for proposers.

Hypothesis 3. The psychological traits of responders and the reputation of the proposers interact producing different evaluations of the offers received by the responders.

\section{Methods and Procedures}

\subsection{Sampling}

The total number of participants was 215 (38 males and 177 females), with an average age of 15.81 (standard deviation 1.29). Few students were over the age of 18 , so they have read and signed the informed consent by themselves, while for all those who were minors, we asked the authorization to their parents or legal guardians. The participation in the experiment was voluntary and consistent with the Italian Psychological Association's guidelines. The following inclusion criteria have been adopted to select the experimental subjects: (1) correct understanding of the Italian language; (2) absence of a learning disabilities diagnosis; and (3) ability to voluntarily express the will to join the experiment. Among all the classes involved in the study, only less than the $5 \%$ of the students did not enter in the study. For the students who did not want to be involved in the research, or who did not have the authorization, or who did not match the inclusion criteria, a freely chosen activity, with the supervision of the teacher, was carried out.

\subsection{The Game}

With the purpose of investigating the individual susceptibility to reputation, we developed a specific software to allow participants to play an online modified version of the Ultimatum Game (UG), in which a reputational system was included. The game was divided into two phases, and the participants always played first as proposers and then as responders for 15 rounds each. Players believed that they were challenging their schoolmates, even if they were playing with bots, and we randomly assigned to each bot a reputation that ranged between -5 and +5 . The participants were informed that the game could be synchronous or asynchronous, namely that they could interact with someone that was playing the game in the same moment, or with someone that had already played 
or that would play in the future. During each round of the donation phase, participants had to make an offer between 0 and 10 euros to their anonymous interactor (i.e., a believed schoolmate but in reality a bot). The only information they had about their opponent was his reputation, represented in the game by green likes for positive, and red dislikes for negative values, while a question mark represented a neutral (i.e., no previous feedback) reputation. After 15 donation rounds, the participants switched to the second phase of the UG, fulfilling the role of the responders. In each round of this phase, the players had to accept or refuse the offer they received from an anonymous interactor (i.e., a believed schoolmate but in reality a bot); furthermore, they also could evaluate the offer they received, through a like or a dislike. Also in this phase of the game, participants knew the opponent's reputation. The system randomly generated the bots' offer, and it ranged between 0 and 10 euros. Both in the donation and the reception phase, participants were told that the reputation of their interactor derived from his previous actions as proposer computed as the Number of Likes-Number of Dislikes. At the end of the game, namely, when all the 30 rounds were completed, the players could see their potential gain. This score resulted from the sum of the accepted offers and the donations they have made as if they were always not refused. Players were informed that their real gain would be communicated at the end of the week of the experiments when all their offers would have been judged.

\subsection{Psychological Measures}

In order to evaluate the potential role of the psychological variables in the susceptibility to fairness and reputation, the participants of the experiment were asked to complete an online survey composed by two sections: the first one included socio-demographic questions, while the second one investigated some psychological constructs. In the first section, players had to provide information about gender, age, and household size. The second section consisted of the following scales: I-TIPI (Italian Ten Items Personality Inventory) [40], STAI (State-Trait Anxiety Inventory) [41] and SDO7 (Social Dominance Orientation) [42].

- I-TIPI [40]. With the intention of estimating the impact of personality on the susceptibility to reputation, we administered to the participants the Italian Ten Items Personality Inventory. The scale is divided into five sub-scales that investigate the areas of Extraversion, Agreeableness, Consciousness, Neuroticism, and Openness. The scale's 10 items are on a five-point Likert, from 1 (strongly disagree) to 5 (strongly agree). The reliability of the entire scale is $\alpha=0.57$.

- $\quad$ STAI [41]. In the experiment, we investigated the involvement of anxiety in determining the susceptibility to reputation, through the State-Trait Anxiety Inventory. It is a four-point scale that goes from 1 (not at all) to 4 (very much so) with 20 items. The Cronbach's alpha of this scale is $\alpha=0.90$.

- $\quad$ SDO7 [42]. In order to evaluate if participants' different levels of social dominance orientation could explain discrepancies in the susceptibility to reputation, we included the SDO7 scale in the survey. The instrument is composed of 16 items self-report on a five-point Likert from 1 (strongly oppose) to 5 (strongly favor). The questionnaire is divided into four sub-scales: Pro-trait Dominance, Con-trait Dominance, Pro-trait Anti-egalitarianism, and Con-trait Anti-egalitarianism, and provide a total score, with a Cronbach's alpha of $\alpha=0.88$.

\subsection{Procedures}

The experiment has been carried out at the "Licei Giovanni da San Giovanni" high-school, in San Giovanni Valdarno (AR) in February 2017, with the participation of the majority of the students of the human sciences section. The experiment required one school-week (from Monday to Friday). Each class, from ninth to the eleventh grade, participated in the experiment, that took at most one hour of lesson. The students were escorted by their teacher to the computer lab where the experimenters were waiting for them. After the initial greetings, the participants received all the information necessary to perform the test and a personal id number, in order to preserve their anonymity. A power-point presentation was projected on the electronic board with the purpose of explaining how to complete the 
survey and the rules of our modified version of the UG online. At the end of the presentation and after answering all the students' questions, the members of the research team brought each participant to his computer station. After all the students had sat down, they were allowed to fill the online survey identifying themselves through the personal id. At the end of the questionnaire, which took about $20 \mathrm{~min}$, the participants were asked to play our online modified version of the UG, inserting their id again to run the game. When all the students finished the experimental session, they received a brief debriefing on the project. Finally, the participants were escorted to their classroom by the teacher. A few weeks after the end of the experiments, all the students took part in a meeting that had the purpose of explaining the project and returning the obtained results.

\subsection{Data Analysis}

After the collected data pre-processing, in order to verify our hypothesis, we assessed the homoscedasticity (i.e., asymmetry and kurtosis) of the continuous variables, used for the parametric analysis. Furthermore, since we employed repeated measure, we adopted the GLMM (Generalised Linear Mixed Model) [43] to explore the mediation effects of personal characteristics on reputation susceptibility.

\section{Results}

Results of the study are presented along five different sub-sections. The first sub-section is dedicated to the description of the participants' socio-demographic characteristics, and their psychological traits. Furthermore, it also includes descriptive statistics for the operative variables (i.e., Offer, Acceptance, Rating). For what concerns the socio-demographic characteristics, we took into account the participants' age and gender, while for what concerns the "psychological traits" we referred to the personality features (i.e., Openness, Conscientiousness, Agreeableness, and Social Dominance Orientation) and the State Anxiety. Furthermore, with regards to the operative variables, we related to those behaviors that we investigated through our online game, namely the Donation amount, the Acceptance rate, and the Rating behavior. The second sub-section focuses on the effects of the socio-demographic characteristics on the Operative Variables, while the third sub-section reports the effects of the interaction between the responders' Reputation and the Psychological Traits of the proposers on the Donation behavior. The fourth sub-section presents the results of the interaction between the proposers' reputation and the responders' Psychological traits on the Acceptance behavior. Finally, the last sub-section focuses on the effects of the proposers' reputation and the Psychological traits of the responder on the Rating behavior (i.e., like and dislike dynamics).

\subsection{Descriptive Statistics}

In this sub-section we presented the descriptive statistics of the participants' socio-demographic characteristics and psychological traits. Furthermore, we included also the operative variables of the study, namely the Donation amount, the Average Acceptance Rate, and the Average Rating Value. From Table 2 emerges that the Age range is particularly narrow. The average Age of the sample is 15.81 (standard deviation 1.29), with a minimum of 14 and a maximum of 19 years old. The sample is composed of 177 females and 38 males, respectively the $82 \%$ and the $18 \%$ of the total subjects. For what concerns the psychological traits, the sample means appear to be adequately balanced, and in line with those of the population. Indeed, our participants show an average value between 6 and 7 points for Openness, Extraversion, Neuroticism, Conscientiousness, and Agreeableness, while within the population it is reported to range between 5 and 7 points. Our sample reports an average score of 48 points in State Anxiety and 35 points in Social Dominance Orientation. Even in this case, the distribution of the values appears as centered on the instruments' mean distribution. Referring to the donation phase, the participants' mean Offer is 3.30 out of 10 euros, while in the population it is reported to be the $42.3 \%$ of the amount at stake [44]. For what concerns the reception phase, the average Acceptance rate is the $68 \%$, while the probability to positive evaluate the offer received (i.e., giving a 
like), independently from the stake, is the $58 \%$. Finally, it is important to note that all the skewness and the kurtosis values of the considered variables are in the range $(-1,1)$; therefore they respect the necessary precondition for the subsequent inferential analysis.

Table 2. Descriptive statistics of Socio-demographic Characteristics and Operative Variables. In the table are reported the psychometric features of the Socio-demographic Characteristics, the Psychological Traits, and the Game's Operative Variables.

\begin{tabular}{cccccc}
\hline \multicolumn{5}{c}{ Descriptive Statistics of Socio-Demographic, Psychological and Operative Variables } \\
\hline Variable & Mean (S.D.) & Skewness & Kurtosis & Min & Max \\
\hline Age & $15.81(1.29)$ & 0.001 & -1.068 & 14 & 19 \\
Openness & $7.21(1.72)$ & -0.387 & -0.068 & 2 & 10 \\
Extraversion & $6.28(2.23)$ & -0.103 & -0.890 & 2 & 10 \\
Neuroticism & $6.39(1.92)$ & -0.251 & -0.362 & 2 & 10 \\
Conscientiousness & $7.14(1.85)$ & -0.302 & -0.370 & 2 & 10 \\
Agreeableness & $7.53(1.73)$ & -0.518 & -0.033 & 2 & 10 \\
State Anxiety & $47.76(10.78)$ & 0.490 & -0.408 & 25 & 76 \\
Social Dominance Orientation & $34.72(9.52)$ & 0.529 & 1.050 & 16 & 73 \\
Offer & $3.30(1.17)$ & 0.235 & -0.280 & 0 & 10 \\
Average Acceptance Rate ${ }^{1}$ & $68 \%(17 \%)$ & 0.006 & -0.027 & $6 \%$ & $100 \%$ \\
Average Rating Rate ${ }^{1}$ & $58 \%(18 \%)-0.460$ & 0.880 & $0 \%$ & $100 \%$ & \\
\hline
\end{tabular}

$1=$ Normalised frequency.

\subsection{Effects of Socio-Demographic Characteristics on Operative Variables}

In this subsection, we explore the relationship between the socio-demographic characteristics (i.e., age and gender), and the operative variables of the experiment. Given the unbalanced sub-samples determined by gender, we adopted a generalized linear mixed model approach to assess the relationship between age, gender and operative variables (i.e., Donation, Acceptance, and Rating behaviors). As shown in Table 3, the socio-demographic characteristics seem to be not related to the "Acceptance" and "Rating" behaviors in our experiment. Only the Gender variable appears to be associated with the "Donation" behavior.

Table 3. Gender effects on Donation behavior.

\begin{tabular}{|c|c|c|c|c|}
\hline \multicolumn{5}{|c|}{ GLMM Best Model for Gender Effect on Donation Behavior } \\
\hline & \multicolumn{2}{|c|}{ Akaike } & $\mathbf{F}$ & Df-1 (2) \\
\hline Best Model & \multicolumn{2}{|c|}{13266.651} & $35.737^{* * *}$ & $4(3222)$ \\
\hline \multicolumn{5}{|c|}{ Fixed effects } \\
\hline Factor & $\mathbf{F}$ & Df-1 (2) & Coefficient $(\beta)$ & Student $t$ \\
\hline Gender (Male) & $35.737^{* * *}$ & $1(3222)$ & 0.507 & $5.978^{* * *}$ \\
\hline
\end{tabular}

In Table 3 is the effect of Gender on Donation behavior. Under our experimental conditions, namely with a reputational system included in the game, males appear to be significantly more generous than Females (3.73 euros vs. 3.22 euros). On average, they offer the 13-15\% more than females. Furthermore, within our sample, the subjects' ages are not significantly related to the donation behavior. Nevertheless, given the narrow range of variation of such dimension within our sample (i.e., 14-19 years old), we consider such result just as a control measure, and not interesting for general considerations. 


\subsection{Effects of the Interaction between Psychological Traits and Reputation on Donation Behavior}

In this subsection, we describe the susceptibility to reputation depending on the psychological traits in the donation phase of the UG. Through a Generalised Linear Mixed Model, we verify our first hypothesis (H1), namely that the participants' allocation behavior is influenced by the Responder's Reputation (RR) and the player's psychological traits. From the results emerge that there is a positive effect of the Responder's Reputation on the amount of virtual money donated; furthermore, a negative effect of Openness and Social Dominance Orientation in interaction with the RR emerges on donation amount (Table 4). In other words, the more the subjects' were open and oriented to the social dominance, the less they donated to opponents with a good reputation, apparently disagreeing (or rejecting) the social norm. The best model accounts for the $60.5 \%$ of the total variance showed by the donation dynamics.

Table 4. Generalised Linear Mixed Models 1. Effects of Reputation and "Reputation Susceptibility" on the Donation Phase.

\begin{tabular}{|c|c|c|c|c|}
\hline \multicolumn{5}{|c|}{ Reputation Susceptibility Effects on Donation Dynamics in the Ultimatum Game } \\
\hline & Akaike & $\mathbf{F}$ & Df-1 (2) & Model Precision \\
\hline Best Model & 3137.053 & $24.939 * * *$ & $3(3220)$ & $60.5 \%$ \\
\hline \multicolumn{5}{|c|}{ Fixed effects } \\
\hline Factor & F & Df-1 (2) & Coefficient $(\beta)$ & Student $t$ \\
\hline Responder Reputation (RR) & $15.820 * * *$ & $1(3220)$ & 0.381 & $3.977^{* * *}$ \\
\hline Openness* RR & $3.442 * *$ & 1(3220) & -0.018 & $-2.155^{* *}$ \\
\hline Social Dominance Orientation * $R R$ & $4.044^{* *}$ & 1(3220) & -0.003 & $-2.011 * *$ \\
\hline
\end{tabular}

\subsection{Effects of the Interaction between Psychological Traits and Reputation on Acceptance Behavior}

With the aim of checking our second assumption (H2), namely the participants' reception behavior, depending on their psychological traits and the proposer's reputation, we employed the GLMM for the repeated measure. The results are presented in Table 5. The acceptance behavior appears to be influenced by the Offer, the Proposer Reputation (PR) and their interaction. In particular, the probability of accepting the offer was higher when the stake was good, and when the proposer had a good reputation. Moreover, the interaction between the Offer and the PR suggests that the acceptance rate of a specific offer would change depending on the proposer's reputation, namely increasing at the increase of their reputation. For what concerns the susceptibility to reputation, those participants with higher values of Openness, Agreeableness, and State Anxiety, seemed to be less prone to accept an offer coming from a good reputation proposer (i.e., reverse effect of reputation). The best model explains the $78.8 \%$ of the total variance showed by the acceptance dynamics.

Table 5. Generalised Linear Mixed Models 2. Effects of Reputation and "Reputation Susceptibility" on the Acceptance Phase.

\begin{tabular}{|c|c|c|c|c|}
\hline \multicolumn{5}{|c|}{ Reputation Susceptibility Effects on Acceptance Dynamics in the Ultimatum Game } \\
\hline & Akaike & $\mathbf{F}$ & Df-1 (2) & Model Precision \\
\hline Best Model & 2852.036 & $104.068^{* * *}$ & $6(3217)$ & $78.8 \%$ \\
\hline \multicolumn{5}{|c|}{ Fixed Effects } \\
\hline Factor & $\mathbf{F}$ & Df-1 (2) & Coefficient $(\beta)$ & Student $t$ \\
\hline Offer & $613.552 * * *$ & $1(3217)$ & 0.567 & $24.770 * * *$ \\
\hline Proposer Reputation (PR) & $10.753 * * *$ & $1(3217)$ & 0.429 & $3.279 * * *$ \\
\hline Offer * PR & $6.443 * * *$ & $1(3217)$ & 0.019 & $2.538 * * *$ \\
\hline Openness * PR & $4.254^{* *}$ & $1(3217)$ & -0.022 & $-2.162 * *$ \\
\hline Agreeableness * PR & $8.653 * * *$ & $1(3217)$ & -0.028 & $-2.942 * * *$ \\
\hline State Anxiety * PR & $5.389 * *$ & $1(3217)$ & -0.004 & $-2.321 * *$ \\
\hline
\end{tabular}




\subsection{Effects of the Interaction between Psychological Variables and Reputation on Offer's Rating}

In this subsection, our interest is oriented towards the effect of reputation, and psychological traits in the rating of the received offers, in order to investigate our third hypothesis (H3). With the term rating, we refer to the possibility that we gave to the players to express a positive or negative judgment on the proposal they received, using a "like" or a "dislike." The magnitude of the Offer, as well as its interaction with the Proposer Reputation, clearly shows a direct effect on the Rating behavior. As shown in Table 6, a proposer with a good reputation received, more probably, a positive rating from the responder respect to a proposer with a low reputation, despite the same amount of virtual money donated. The greatest susceptibility to reputation was shown by participants with extreme scores in Conscientiousness and Agreeableness, while modest but significant effects, emerged for players with high values of State Anxiety and Social Dominance Orientation. Those participants who registered the highest score on Conscientiousness appeared more prone to positively evaluate an offer just because it came from a proposer with a good reputation, showing a tendency to adhere to the social norm (scaffolding) provided by the reputation itself. In the same direction, also the Social Dominance Orientation trait seems to be associated with the tendency to be biased by the reputation of the proposer during the rating phase. On the contrary, the Agreeableness and the State Anxiety traits seem "negatively susceptible" to the reputation of the proposer. In fact, participants with high scores in this dimensions appeared to decrease the positively of their evaluations when the Proposer Reputation increased. The best model explains the $75.3 \%$ of the total variance shown by the rating dynamics.

Table 6. Generalised Linear Mixed Models 3. Effects of Reputation and "Reputation Susceptibility" on the Rating Phase.

\begin{tabular}{ccccc}
\hline \multicolumn{5}{c}{ Reputation Susceptibility Effects on Rating Dynamics in the Ultimatum Game } \\
\hline & Akaike & F & Df-1(2) & Model Precision \\
\hline Best Model & 3331.810 & $111.330^{* * *}$ & $6(3217)$ & $75.3 \%$ \\
\hline \multicolumn{5}{c}{ Fixed effects } \\
\hline Factor & F & Df-1(2) & Coefficient $(\boldsymbol{\beta})$ & Student $t$ \\
\hline Offer & $652.285^{* * *}$ & $1(3217)$ & 0.458 & $25.540^{* * *}$ \\
Offer * Proposer Reputation (PR) & $4.677^{* *}$ & $1(3217)$ & 0.013 & $2.163^{* *}$ \\
Conscientiousness *(PR) & $8.289^{* * *}$ & $1(3217)$ & 0.019 & $2.879^{* * *}$ \\
Agreeableness *(PR) & $6.961^{* * *}$ & $1(3217)$ & -0.021 & $-2.638^{* * *}$ \\
State Anxiety *(PR) & $16.502^{* * *}$ & $1(3217)$ & -0.004 & $-4.062^{* * *}$ \\
Social Dominance Orientation *(PR) & $10.405^{* * *}$ & $1(3217)$ & 0.004 & $3.226^{* * *}$ \\
\hline
\end{tabular}

$* * *=p<0.001 ; * *=p<0.05$. Note: ${ }^{*}=$ Interaction with.

\section{Discussion}

The main interest of this study was to investigate the peoples' susceptibility to reputation in the online environment, through a modified version of the Ultimatum Game. Overall, our work sheds light on the mediation role played by the psychological variables on the relationship between online reputation and UG behaviors. Through the exploration of the players' behavior and their tendency to positively or negatively rate their opponents, our findings showed that reputation could affect people's online social decision making (i.e., donation, acceptance and rating behaviors). In particular, in accordance with the literature, acceptance was more likely when facing well-reputed proposers [33], in fact equally fair players (i.e., that exhibited the same offer to the responders) were evaluated differently according to their reputational rating [39]. Furthermore, well-rated responders received more generous offers. In this sense, the simple fact to assign a good reputation to an opponent appeared to be sufficient to prompt individuals to reward them with higher offers. This evidence is in line with previous findings and extends to a slightly different domain and under other circumstances, the results coming from public good games literature [45]. For what concerns the offers made by 
our participants, we observed gender differences, with the males acting fairer than the females. Despite recent works suggesting that women are in general more altruistic than men in the Dictator game [46], our results appeared to be in line with a recent work of Duradoni et al. [47] concerning adolescents, in which the presence of a reputational system in a Bargaining Game, induced males to be more generous than females. Thus, one could hypothesize that such differences can be attributed to distinct susceptibility to the reputation of males and females, even if only in allocation tasks. The central aspect of our findings relates to the role of psychological variables in mediating the relationship between reputation and UG behaviors. As reported in Table 7, we compared the expected effects of reputation susceptibility of psychological variables derived from the literature with those obtained in our study. As regards Anxiety trait, literature predictions were fully confirmed. In fact, high-Anxious individuals appeared less susceptible to the normative influence of reputation. On the one hand, they did not offer, on average, different amounts towards individuals with good or bad reputation; on the other, they accepted less frequently the offers coming from well-rated proposers. Moreover, the high-Anxious participants seemed to be less prone to reward well-rated proposers with positive feedback. As regards Openness trait, it was confirmed as a factor that can hinder compliance with social norms. Individuals characterized by high Openness resulted to offer lower stakes to well-reputed responders, as well as to accept less frequently proposals coming from well-reputed opponents. They also appeared to ignore the proposers' reputation in their rating decision-making process (i.e., they rated independently from proposers' reputation). Literature predictions regarding the relationship between Conscientiousness and reputation susceptibility resulted mainly unconfirmed. Since conscientious individuals are known to be task-oriented and goal-directed [48], the explanation could be found in the UG framework itself (i.e., strategic self-interested framework). In our game, reputation was not directly affecting the UG dynamics and the absence of reputation susceptibility showed by individuals with high Conscientiousness can be considered as actually not in conflict with the previous findings. Nevertheless, in the rating phase Conscientious individuals actively enhance the social norm (i.e., reputation) providing more positive evaluation towards already well-reputed proposers. In this case, results appeared to confirm the expected tendency of conscientious subjects to promote the group or local norms. For what concerns literature-based expectations regarding the trait of Social Dominance Orientation and reputation susceptibility, they were partially not confirmed. In fact, we expected high-SDO individuals to be equally fair to all targets, or at least to be more generous with well-reputed responders [26,49]. Nevertheless, in our experiment, we found that the high-SDO individuals offered smaller stakes to well-reputed responders, while they were not affected by proposers' reputation when deciding whether accept or not the received offer. Instead, the tendency of high-SDO individuals to be sensitive to proposers' reputation emerged as in line with their group-based hierarchy preference [50]. Our study did not confirm literature predictions about the reputation sensitivity related to the trait of Agreeableness. Indeed, within our computer-mediated environment, high Agreeableness individuals did not act more pro-socially. A possible explanation for this result can be identified in the link between self-reported Agreeableness and social desirability (i.e., the desire to manage social impressions) [51]. Because of deindividuation dynamics [32], in an environment where offers are completely anonymous, the relationship between Agreeableness and pro-social behaviors could be inconsistent [52]. Interestingly, in the acceptance phase of our game, responders with a high Agreeableness tended to prefer allocations coming from bad-reputed proposers. This finding seems to confirm the claim of Yarkoni, Ashar, and Wager [53], who highlighted, in an online study, how high-Agreeable individuals overlooked the risk of proposers' negative behaviors. Moreover, high-Agreeableness individuals evaluated more positively proposers with a bad reputation. In this sense, their evaluation could be explained with what reported by Graziano et al. [54] regarding the tendency of high-Agreeableness individuals to evaluate more positively stigmatized social groups. Apart from our results, it appears that more efforts are required to fully understand how Agreeableness trait influences the subjects' interpretation and perception of online social norms (i.e., reputation). Finally, no relationship between Extraversion and Neuroticism traits with the reputation has been 
found in our study, probably because of the effects of deindividuation in online environments. In conclusion, our work examined how reputation could affect online behaviors (e.g., donation, acceptance, and rating), in relation to the psychological traits of the individuals. Despite in our online version of the Ultimatum Game the reputation was not influencing the game dynamics directly, people actually relied much on their opponents' reputation in the decision making processes. Beyond the direct effects of reputation on individuals' behavior, a complex scenario emerged for the reputation susceptibility due to psychological traits. In particular, some personal characteristics appear to catalyze reputation social influence (i.e., favoring the decision-making biases based on reputation), while others act in the opposite direction as "protective" factors. Our results can be useful to design web-based services and platforms, in particular in those cases in which reputation biases would represent a factor reducing the system's effectiveness and robustness [55-58].

Table 7. Results and Experimental Hypotheses: in table is reported the comparison between the predictions derived by the existing literature, and the experimental results.

\begin{tabular}{|c|c|c|c|c|c|c|}
\hline \multicolumn{7}{|c|}{ Comparison between Experimental Hypotheses and Results } \\
\hline \multirow[b]{2}{*}{ Variable } & \multicolumn{2}{|c|}{$H_{1}$ : Donation } & \multicolumn{2}{|c|}{$\mathrm{H}_{2}$ : Acceptance } & \multicolumn{2}{|c|}{$H_{3}$ : Rating } \\
\hline & Hyp & Res & Hyp & Res & Hyp & Res \\
\hline Reputation & + & + & + & + & + & + \\
\hline Openness * $\mathrm{R}$ & - & - & - & - & 0 & 0 \\
\hline Conscientiousness ${ }^{*} \mathrm{R}$ & + & 0 & + & 0 & + & + \\
\hline Agreeableness * $\mathrm{R}$ & + & 0 & + & - & + & - \\
\hline State Anxiety * $\mathrm{R}$ & 0 & 0 & - & - & - & - \\
\hline Social Dominance Orientation * $R$ & + & - & + & 0 & + & + \\
\hline
\end{tabular}

Author Contributions: S.C carried out the experiments. A.G. conceived the original idea. S.C. and S.P. wrote the manuscript with support from E.I., F.S., and M.D. A.G. conducted the statistical analysis. A.G. supervised the whole project. All the authors revised the manuscript the manuscript.

Funding: This research received no external funding.

Acknowledgments: A special acknowledgement goes to "Licei Giovanni da San Giovanni", that contributed to the implementation of the experiment. We also thank all the teachers that gave their willingness to participate in this experience. Thanks to Franco Bagnoli for his contribution in the development of the software.

Conflicts of Interest: The authors declare no conflict of interest.

\section{References}

1. Kimbrough, E.O.; Vostroknutov, A. Norms make preferences social. J. Eur. Econ. Assoc. 2016, 14, 608-638. [CrossRef]

2. Henrich, J.; Boyd, R.; Bowles, S.; Camerer, C.; Fehr, E.; Gintis, H.; McElreath, R. In search of homo economicus: Behavioral experiments in 15 small-scale societies. Am. Econ. Rev. 2001, 91, 73-78. [CrossRef]

3. Sanfey, A.G. Social decision-making: Insights from game theory and neuroscience. Science 2007, 318, 598-602. [CrossRef] [PubMed]

4. Page, K.M.; Nowak, M.A.; Sigmund, K. The spatial ultimatum game. Proc. R. Soc. Lond. B Biol. Sci. 2000, 267, 2177-2182. [CrossRef]

5. Güth, W.; Schmittberger, R.; Schwarze, B. An experimental analysis of ultimatum bargaining. J. Econ. Behav. Organ. 1982, 3, 367-388. [CrossRef]

6. Güth, W.; Kocher, M. More than thirty years of ultimatum bargaining experiments: Motives, variations, and a survey of the recent literature. J. Econ. Behav. Organ. 2014, 108, 396-409. [CrossRef]

7. Gabay, A.S.; Radua, J.; Kempton, M.J.; Mehta, M.A. The Ultimatum Game and the brain: A meta-analysis of neuroimaging studies. Neurosci. Biobehav. Rev. 2014, 47, 549-558. [CrossRef]

8. Fehr, E.; Schmidt, K.M. A theory of fairness, competition, and cooperation. Q. J. Econ. 1999, 114, 817-868. [CrossRef] 
9. Capraro, V. Social versus Moral preferences in the Ultimatum Game: A theoretical model and an experiment. arXiv 2018, arXiv:1804.01044.

10. Castelli, I.; Massaro, D.; Bicchieri, C.; Chavez, A.; Marchetti, A. Fairness norms and theory of mind in an ultimatum game: Judgments, offers, and decisions in school-aged children. PLoS ONE 2014, 9, e105024. [CrossRef]

11. Feng, C.; Luo, Y.J.; Krueger, F. Neural signatures of fairness-related normative decision making in the ultimatum game: A coordinate-based meta-analysis. Hum. Brain Mapp. 2015, 36, 591-602. [CrossRef] [PubMed]

12. Nowak, M.A.; Page, K.M.; Sigmund, K. Fairness versus reason in the ultimatum game. Science 2000, 289, 1773-1775. [CrossRef]

13. Wu, J.; Balliet, D.; Van Lange, P.A. Reputation, gossip, and human cooperation. Soc. Personal. Psychol. Compass 2016, 10, 350-364. [CrossRef]

14. Debove, S.; Baumard, N.; André, J.B. Models of the evolution of fairness in the ultimatum game: A review and classification. Evol. Hum. Behav. 2016, 37, 245-254. [CrossRef]

15. Capraro, V.; Giardini, F.; Vilone, D.; Paolucci, M. Partner selection supported by opaque reputation promotes cooperative behavior. Judgm. Decis. Mak. 2016, 11, 589-600.

16. Bicchieri, C.; Chavez, A. Behaving as expected: Public information and fairness norms. J. Behav. Decis. Mak. 2010, 23, 161-178. [CrossRef]

17. Conte, R.; Paolucci, M. Reputation in Artificial Societies: Social Beliefs for Social Order; Springer: Berlin/Heidelberg, Germany, 2002; Volume 6,

18. Giardini, F.; Conte, R. Gossip for social control in natural and artificial societies. Simulation 2012, 88, 18-32. [CrossRef]

19. Baumeister, R.F.; Zhang, L.; Vohs, K.D. Gossip as cultural learning. Rev. Gen. Psychol. 2004, 8, 111. [CrossRef]

20. Webster, M.M.; Ward, A.J. Personality and social context. Biol. Rev. 2011, 86, 759-773. [CrossRef]

21. Becker, A.; Deckers, T.; Dohmen, T.; Falk, A.; Kosse, F. The relationship between economic preferences and psychological personality measures. Annu. Rev. Econ. 2012, 4, 453-478. [CrossRef]

22. Dohmen, T.; Falk, A.; Huffman, D.; Sunde, U. Representative trust and reciprocity: Prevalence and determinants. Econ. Inq. 2008, 46, 84-90. [CrossRef]

23. Lang, H.; DeAngelo, G.; Bongard, M. Theory of Mind and General Intelligence in Dictator and Ultimatum Games. Games 2018, 9, 16. [CrossRef]

24. Costa, P.T., Jr.; McCrae, R.R. Four ways five factors are basic. Personal. Individ. Differ. 1992, 13, $653-665$. [CrossRef]

25. DeYoung, C.G.; Peterson, J.B.; Higgins, D.M. Higher-order factors of the Big Five predict conformity: Are there neuroses of health? Personal. Individ. Differ. 2002, 33, 533-552. [CrossRef]

26. Armstrong, J. Tough but Fair: The Moderating Effects of Target Status on the Relation between Social Dominance Orientation and Fairness. Ph.D. Thesis, Electronic Thesis and Dissertation Repository. 1382. The University of Western Ontario. 2013. Available online: https://ir.lib.uwo.ca/etd/1382 (accessed on 30 November 2018)

27. Wu, T.; Luo, Y.; Broster, L.S.; Gu, R.; Luo, Y.J. The impact of anxiety on social decision-making: Behavioral and electrodermal findings. Soc. Neurosci. 2013, 8, 11-21. [CrossRef] [PubMed]

28. Prinstein, M.J.; Brechwald, W.A.; Cohen, G.L. Susceptibility to peer influence: Using a performance-based measure to identify adolescent males at heightened risk for deviant peer socialization. Dev. Psychol. 2011, 47, 1167. [CrossRef]

29. Crone, E.A. Considerations of fairness in the adolescent brain. Child Dev. Perspect. 2013, 7, 97-103. [CrossRef]

30. Rasooli, A.; Zandi, H.; DeLuca, C. Re-conceptualizing classroom assessment fairness: A systematic meta-ethnography of assessment literature and beyond. Stud. Educ. Eval. 2018, 56, 164-181. [CrossRef]

31. McKenna, K.Y.; Bargh, J.A. Plan 9 from cyberspace: The implications of the Internet for personality and social psychology. Personal. Soc. Psychol. Rev. 2000, 4, 57-75. [CrossRef]

32. Postmes, T.; Spears, R.; Sakhel, K.; De Groot, D. Social influence in computer-mediated communication: The effects of anonymity on group behavior. Personal. Soc. Psychol. Bull. 2001, 27, 1243-1254. [CrossRef]

33. Qi, S.; Footer, O.; Camerer, C.; Mobbs, D. A collaborator's reputation can bias decisions and anxiety under uncertainty. J. Neurosci. 2018, 38, 2262-2269. [CrossRef] [PubMed] 
34. Jensen-Campbell, L.A.; Rosselli, M.; Workman, K.A.; Santisi, M.; Rios, J.D.; Bojan, D. Agreeableness, conscientiousness, and effortful control processes. J. Res. Personal. 2002, 36, 476-489. [CrossRef]

35. Paulhus, D.L.; John, O.P. Egoistic and moralistic biases in self-perception: The interplay of self-deceptive styles with basic traits and motives. J. Personal. 1998, 66, 1025-1060. [CrossRef]

36. Graziano, W.G.; Eisenberg, N. Agreeableness: A dimension of personality. In Handbook of Personality Psychology; Elsevier: Amsterdam, The Netherlands, 1997; pp. 795-824.

37. Roberts, G. Reputation and Altruism. In Encyclopedia of Evolutionary Psychological Science; Shackelford,T.K., Weekes-Shackelford, V.A., Eds.; Springer International Publishing: Cham, Switzerland, 2017.

38. Henrich, J.; McElreath, R.; Barr, A.; Ensminger, J.; Barrett, C.; Bolyanatz, A.; Cardenas, J.C.; Gurven, M.; Gwako, E.; Henrich, N.; et al. Costly punishment across human societies. Science 2006, 312, 1767-1770. [CrossRef] [PubMed]

39. Duradoni, M.; Bagnoli, F.; Guazzini, A. "Reputational Heuristics" Violate Rationality: New Empirical Evidence in an Online Multiplayer Game. In Proceedings of the 2017 International Conference on Internet Science, Thessaloniki, Greece, 22-24 November 2017; pp. 370-376.

40. Chiorri, C.; Bracco, F.; Piccinno, T.; Modafferi, C.; Battini, V. Psychometric properties of a revised version of the Ten Item Personality Inventory. Eur. J. Psychol. Assess. 2015, 31, 109-119 [CrossRef]

41. Spielberg, C.D.; Gorsuch, R.L.; Lushene, R.E.; Vagg, P.R.; Jacobs, G.A. Manual for the State-Trait Anxiety Inventory; Consulting Psychologists Press: Palo Alto, CA, USA, 1970.

42. Ho, A.K.; Sidanius, J.; Kteily, N.; Sheehy-Skeffington, J.; Pratto, F.; Henkel, K.E.; Foels, R.; Stewart, A.L. The nature of social dominance orientation: Theorizing and measuring preferences for intergroup inequality using the new SDO7 scale. J. Personal. Soc. Psychol. 2015, 109, 1003. [CrossRef] [PubMed]

43. McCulloch, C.; Searle, S.; Neuhaus, J. Generalized, Linear, and Mixed Models; Wiley-Interscience: New York, NY, USA, 2001.

44. Tisserand, J.C. Ultimatum game: A meta-analysis of the past three decades of experimental research. In Proceedings of the International Academic Conferences; International Institute of Social and Economic Sciences: Prague, Czech Republic, 2014; ISBN 978-80-87927-05-2.

45. Semmann, D.; Krambeck, H.J.; Milinski, M. Reputation is valuable within and outside one's own social group. Behav. Ecol. Sociobiol. 2005, 57, 611-616. [CrossRef]

46. Brañas-Garza, P.; Capraro, V.; Ramírez, E.R. Gender differences in altruism on Mechanical Turk: Expectations and actual behaviour. Econ. Lett. 2018, 170, 19-23. [CrossRef]

47. Duradoni, M.; Paolucci, M.; Bagnoli, F.; Guazzini, A. Fairness and Trust in Virtual Environments: The Effects of Reputation. Future Internet 2018, 10, 50. [CrossRef]

48. John, O.P.; Srivastava, S. The Big Five trait taxonomy: History, measurement, and theoretical perspectives. Handb. Personal. Theory Res. 1999, 2, 102-138.

49. Halabi, S.; Dovidio, J.F.; Nadler, A. When and how do high status group members offer help: Effects of social dominance orientation and status threat. Polit. Psychol. 2008, 29, 841-858. [CrossRef]

50. Pratto, F.; Sidanius, J.; Stallworth, L.M.; Malle, B.F. Social dominance orientation: A personality variable predicting social and political attitudes. J. Personal. Soc. Psychol. 1994, 67, 741. [CrossRef]

51. Graziano, W.G.; Tobin, R.M. Agreeableness: Dimension of personality or social desirability artifact? J. Personal. 2002, 70, 695-728.

52. DellaVigna, S.; List, J.A.; Malmendier, U. Testing for altruism and social pressure in charitable giving. Q. J. Econ. 2012, 127, 1-56. [CrossRef] [PubMed]

53. Yarkoni, T.; Ashar, Y.K.; Wager, T.D. Interactions between donor Agreeableness and recipient characteristics in predicting charitable donation and positive social evaluation. PeerJ 2015, 3, e1089. [CrossRef] [PubMed]

54. Graziano, W.G.; Habashi, M.M.; Sheese, B.E.; Tobin, R.M. Agreeableness, empathy, and helping: A person $\times$ situation perspective. J. Personal. Soc. Psychol. 2007, 93, 583. [CrossRef] [PubMed]

55. Amato, F.; Moscato, V.; Picariello, A.; Sperlí, G. Diffusion Algorithms in Multimedia Social Networks: A preliminary model. In Proceedings of the 2017 IEEE/ACM International Conference on Advances in Social Networks Analysis and Mining 2017, Sydney, Australia, 31 July-3 August 2017; pp. 844-851.

56. Amato, F.; Moscato, V.; Picariello, A.; Piccialli, F.; Sperlí, G. Centrality in heterogeneous social networks for lurkers detection: An approach based on hypergraphs. Concurr. Comput. Pract. Exp. 2018, 30, e4188. [CrossRef] 
57. Goswami, A.; Gupta, R.; Parashari, G.S. Reputation-based resource allocation in P2P systems: A game theoretic perspective. IEEE Commun. Lett. 2017, 21, 1273-1276. [CrossRef]

58. Shi, Z.; Wei, J.; Wei, X.; Tan, K.; Wang, Z. The task allocation model based on reputation for the heterogeneous multi-robot collaboration system. In Proceedings of the 2010 8th World Congress on Intelligent Control and Automation (WCICA), Jinan, China, 7-9 July 2010; pp. 6642-6647.

(C) 2018 by the authors. Licensee MDPI, Basel, Switzerland. This article is an open access article distributed under the terms and conditions of the Creative Commons Attribution (CC BY) license (http:/ / creativecommons.org/licenses/by/4.0/). 